\title{
KONSUMSI GULA SEDERHANA DAN AKTIFITAS FISIK SEBAGAI FAKTOR RISIKO KEJADIAN HIPERTENSI OBESITIK PADA REMAJA AWAL
}

\author{
Aljannah Rabaity, Muhammad Sulchan ${ }^{*}$ \\ Program Studi Ilmu Gizi Fakultas Kedokteran Universitas Diponegoro \\ Jl.Dr.Sutomo No.14, Semarang, Telp (024) 8453708, Email : gizifk@undip.ac.id
}

\begin{abstract}
Background: According to riskesdas 2007 in Indonesia, the prevalence of hypertension in adolescents by 9\%. The prevalence of obesitic in adolescents according to Riskesdas 2010 by 19,1\%. This study aims to determine the consumption of refined sugars and physical activity as risk factors the incident hypertension obesitic in early adolescence.

Methods: The study was conducted in 5 SMP in Semarang. Case-control study design with a number of 76 subjects consisting of 38 cases and 38 controls. Selection of study sample by using proportional random sampling of classes 7 and 8. Data obtained from a refined sugar intake interview directly Food Frequency Questionnaire method (FFQ). Blood pressure samples measured using a sphygmomanometer.

Results: The prevalence of obesitic hypertension is $7.5 \%$. In this study, it is found that there is a significant correlation between refined sugars intake $(O R=2,6 ; C I=1,041-6,636 ; p=0,039)$ physical activity $(O R=3,5$; $C I=1,267-10,143 ; p=0,014)$ on hypertension obesitic occurance on early adolescence.

Conclusion: Refined sugars intake and physical activity are significant risk factor of hypertension obesitic on early adolescence, that risk factors respectively 2.6 times and 3.5 times.
\end{abstract}

Key words: simple sugars; physical activity; obesitic and hypertension

\begin{abstract}
ABSTRAK
Latar Belakang: Menurut Riskesdas tahun 2007 di Indonesia, prevalensi hipertensi pada remaja sebesar 9\%. Prevalensi obesitik pada remaja menurut Riskesdas 2010 sebesar 19,1\%. Penelitian ini bertujuan untuk mengetahui konsumsi gula sederhana dan aktifitas fisik sebagai faktor risiko kejadian hipertensi obesitik pada remaja awal.

Metode : Penelitian dilakukan di 5 SMP di Semarang. Desain penelitian kasus kontrol dengan jumlah subyek sebesar 76 yang terdiri dari 38 kasus dan 38 kontrol. Pemilihan sampel penelitian dengan menggunakan proportional random sampling dari kelas 7 dan 8. Data asupan gula sederhana diperoleh dari wawancara secara langsung menggunakan metode Food Frequency Questionnaire (FFQ). Tekanan darah sampel diukur menggunakan sphygmomanometer.

Hasil : Prevalensi hipertensi obesitik sebesar 7,5\%. Pada penelitian ini ditemukan hubungan yang bermakna antara asupan gula sederhana $(O R=2,6 ; C I=1,041-6,636 ; p=0,039)$ dan aktivitas fisik $(O R=3,5 ; C I=1,267$ - 10,143; $p=0,014)$ terhadap kejadian hipertensi obesitik pada remaja awal.

Simpulan : Asupan gula sederhana dan aktivitas fisik merupakan faktor risiko yang bermakna terhadap kejadian hipertensi obesitik pada remaja awal, dengan besar risiko 2,6 kali dan 3,5 kali.
\end{abstract}

Kata kunci : Gula sederhana; aktifitas fisik; dan hipertensi obesitik

\section{PENDAHULUAN}

Remaja merupakan individu yang sedang berada pada masa peralihan dari masa anak-anak menuju masa dewasa dan ditandai dengan perkembangan yang sangat cepat dari aspek fisik, psikis dan sosial. Masa remaja mulai dihadapkan dengan berbagai masalah, salah satunya yaitu masalah perilaku makan. Masalah ini umumnya disebabkan oleh pola makan yang kurang tepat karena dipengaruhi dua hal, antara lain faktor lingkungan dan faktor personal atau individu dari remaja itu sendiri. Banyak remaja yang tidak memahami kandungan zat gizi dalam makanan dan manfaatnya sehingga remaja cenderung mengkonsumsi makanan cepat saji, makanan dan minuman manis yang tinggi kalori namun kandungan zat gizinya rendah. Hal ini memungkinkan terjadinya kasus obesitik pada remaja. Penyakit yang biasa menyertai obesitik adalah tekanan darah tinggi atau hipertensi.

Tekanan darah tinggi atau hipertensi adalah kondisi medis di mana terjadi peningkatan tekanan darah secara kronis. Hipertensi termasuk penyakit yang tidak menunjukkan tanda-tanda jelas, sebagian besar penyebabnya pun masih banyak diteliti. Hipertensi berarti tekanan tinggi di 
dalam arteri yang dapat menyebabkan meningkatnya risiko terhadap stroke, gagal jantung, serangan jantung dan kerusakan ginjal. Tekanan darah sistolik yang normal adalah antara 90 dan $120 \mathrm{mmHg}$ sedangkan tekanan darah diastolik normal adalah antara 60 dan $80 \mathrm{mmHg}$. Tekanan darah di atas 140/90 termasuk tekanan darah tinggi. ${ }^{1}$ Jumlah penderita hipertensi di seluruh dunia terus meningkat, prevalensi hipertensi pada orang dewasa di Amerika Utara sebesar 28\%, di Eropa Barat sebesar $44 \%$ dan di Afrika sebesar $28,7 \% .^{2}$ Prevalensi hipertensi akan terus meningkat apabila angka kejadian obesitik meningkat, obesitik juga akan terus meningkat apabila tidak disertai dengan aktivitas fisik yang cukup karena aktivitas fisik berhubungan erat dengan terjadinya obesitik dan hipertensi. ${ }^{3}$

Obesitik merupakan suatu keadaan dimana lemak disimpan secara berlebihan didalam tubuh. Obesitik yang terjadi disebabkan oleh banyak faktor, faktor utamanya adalah ketidakseimbangan asupan energi dengan keluaran energi. Obesitik pada masa anak-anak diketahui memiliki dampak yang signifikan terhadap kesehatan baik fisik maupun psikologis. Dewasa ini prevalensi obesitik pada anak usia sekolah meningkat tajam dari tahun sebelumnya, tidak saja di Indonesia, tapi juga di dunia. Di Negara maju obesitik pada anak sudah tinggi, 25\% anak anak-anak di AS mengalami overweight dan $11 \%$ mengalami obesitik. ${ }^{4}$ Sedangkan menurut Riskesdas Provinsi Jawa Tengah 2010, prevalensi obesitik pada remaja sebesar $19,1 \%$. Ditinjau dari pola makan, anakanak merupakan kelompok yang peka terhadap pengaruh lingkungan luar seperti maraknya iklan makanan siap santap (fast food) dan jajanan yang umumnya mengandung kalori tinggi, kaya lemak, tinggi natrium dan rendah serat serta banyak mengandung gula. ${ }^{5}$ Apabila pola makan anak tidak diperhatikan kemungkinan besar kejadian obesitik akan terus meningkat.

Gula sederhana terdiri dari monosakarida dan disakarida, monosakarida terdiri dari glukosa, glaktosa dan fruktosa sedangkan yang termasuk disakarida meliputi sukrosa, laktosa dan maltose. Saat ini asupan makanan yang mengandung fruktosa mengalami peningkatan, jumlah ini semakin bertambah terutama dari penambahan gula termasuk sukrosa. Penelitian terbaru menunjukkan bahwa fruktosa berpengaruh terhadap timbulnya hipertensi. Konsumsi fruktosa meningkat secara drastis selama beberapa tahun terakhir ini, sehingga fruktosa berkontribusi besar terhadap terjadinya obesitik. ${ }^{6}$ Selain konsumsi gula sederhana, faktor yang berpengaruh terhadap terjadinya obesitik adalah aktifitas fisik.

Aktifitas fisik didefinisikan sebagai gerakan tubuh yang dihasilkan oleh otot rangka yang memerlukan pengeluaran energi. Aktifitas fisik yang kurang berhubungan dengan meningkatnya risiko obesitik dan hipertensi. Saat ini di Amerika merekomendasikan agar remaja mulai meningkatkan aktivitas fisiknya selama 1500 menit/minggu atau sekitar 3,5 jam/hari. Para peneliti di Amerika menjelaskan bahwa melakukan aktivitas fisik paling sedikit 15 menit dalam sehari diperkirakan dapat menurunkan $14 \%$ risiko hipertensi obesitik yang dapat menyebabkan kematian. $^{7}$

Penelitian ini bertujuan untuk mengetahui besar risiko asupan gula sederhana dan aktifitas fisik terhadap kejadian hipertensi obesitik pada remaja awal.

\section{METODE PENELITIAN}

Penelitian ini merupakan penelitian analitik observasional dalam bidang gizi masyarakat dengan rancangan case control study yang dilakukan pada bulan Mei-Juni 2012.

Penelitian diawali dengan melakukan screening terhadap seluruh siswa yang meliputi berat badan, tinggi badan, lingkar pinggang, denyut nadi, dan tekanan darah untuk mendapatkan prevalensi hipertensi obesitas. Dari 212 Sekolah Menengah Pertama yang ada di Semarang, di pilih 5 Sekolah Menengah Pertama dengan menggunakan teknik proportional random sampling sehingga didapatkan 2 SMP negeri, 2 SMP swasta dan 1 Madrasah Tsanawiyah. Setelah itu dilakukan teknik simple random sampling untuk mengambil sampel anggota populasi dan didapatkan SMP N 3 Semarang, SMP N 30 Semarang, SMP Ksatrian 2 Semarang, SMP 10 November Semarang, dan MTS Al Khoiriyah. Setelah didapatkan 5 SMP tersebut, dilakukan pengukuran antropometri tinggi badan dengan menggunakan microtoise yang memiliki ketelitian $0,1 \mathrm{~cm}$ dan berat badan menggunakan timbangan injak digital yang memiliki ketelitian $0,1 \mathrm{~kg}$, serta pengukuran tekanan darah dengan menggunakan sphygmomanometer air raksa dengan ukuran panjang $17-19 \mathrm{~cm}$ dan lebar $7-9 \mathrm{~cm}$.

Penelitian selanjutnya dilakukan di 4 SMP yaitu SMP Negeri 3, SMP Negeri 30, SMP Ksatrian 2 dan MTs. Al Khoiriyah, dalam penelitian ini SMP 10 November tidak diikutsertakan karena pertimbangan angka kejadian hipertensi obesitik di SMP 10 November sangat 
rendah yaitu sebesar $0,027 \%$. Besar sampel minimal masing-masing berjumlah 38 kasus (hipertensi obesitik) dan 38 kontrol (normal) dihitung dengan menggunakan rumus case control berpasangan. Data yang dikumpulkan meliputi data asupan gula sederhana dan aktifitas fisik, data asupan gula sederhana menggunakan formulir FFQ (Food Frequency Quesioner). Asupan gula sederhana tinggi jika > $300 \mathrm{mg}$ per hari dan normal jika $\leq 300 \mathrm{mg}$ per hari. ${ }^{8}$ Aktifitas fisik dihitung berdasarkan lama waktu responden beraktifitas baik aktifitas ringan maupun berat yang diperoleh melalui wawancara dengan pengisian kuesioner tentang aktifitas fisik. Aktifitas fisik tergolong normal jika $\geq 1500$ menit/minggu $(3,5$ jam/hari) dan tergolong rendah jika $<1500$ menit/minggu. ${ }^{9}$

$$
\text { Pengolahan dan analisis data }
$$

menggunakan komputerisasi. Derajat obesitik yang dinyatakan dalam persentil $\mathrm{BB} / \mathrm{TB}$ dihitung menggunakan software WHO Anthroplus. Data yang berskala kategorik seperti jenis kelamin, usia, kategori hipertensi obesitik, kategori asupan gula sederhana dan kategori aktifitas fisik dideskripsikan sebagai distribusi frekuensi dan persen. Analisis bivariat menggunakan uji Chi Square dengan tingkat kesalahan 5\%.

\section{HASIL PENELITIAN \\ Karakteristik Subyek}

Hasil penelitian pendahuluan menunjukkan 355 subyek termasuk hipertensi (30,03\%), 155 subyek adalah obesitik $(13,11 \%)$, dan 89 anak termasuk dalam hipertensi obesitik $(7,52 \%)$. Pada penelitian ini melibatkan 76 subyek penelitian yang terdiri dari 38 subyek sebagai kelompok kasus dan 38 subyek sebagai kelompok kontrol.

Karakteristik subyek penelitian dapat dilihat pada tabel 1 .

Tabel 1. Karakteristik subyek penelitian berdasarkan usia dan jenis kelamin

\begin{tabular}{lccc}
\hline \multicolumn{1}{c}{ Karakteristik } & Kasus $(\mathbf{n = 3 8})$ & Kontrol $(\mathbf{n = 3 8})$ & Total \\
\hline Jenis Kelamin & & & \\
Laki-laki & $23(60,5 \%)$ & $23(60,5 \%)$ & 46 \\
Perempuan & $15(39,5 \%)$ & $15(39,5 \%)$ & 30 \\
$\quad$ Total & $38(100 \%)$ & $38(100 \%)$ & 76 \\
Usia & & & \\
12 tahun & $4(10,5 \%)$ & $4(10,5 \%)$ & 8 \\
13 tahun & $17(44,7 \%)$ & $17(44,7 \%)$ & 34 \\
14 tahun & $17(44,7 \%)$ & $17(44,7 \%)$ & 34 \\
Total & $38(100 \%)$ & $38(100 \%)$ & 76 \\
\hline
\end{tabular}

Jenis kelamin subyek penelitian adalah 46 anak laki-laki $(60,5 \%)$ dan anak perempuan sebanyak 30 anak $(39,5 \%)$. Subyek dengan umur termuda adalah 12 tahun dan umur tertua adalah 14 tahun. Subyek berusia 12 tahun sebanyak 8 anak $(10,5 \%), 13$ tahun sebanyak 34 anak $(44,7 \%)$ dan 14 tahun sebanyak 34 anak $(44,7 \%)$.

\section{Tekanan Darah}

Penentuan persentil tekanan darah disesuaikan dengan usia, jenis kelamin dan tinggi badan. Distribusi tekanan darah dapat dilihat pada tabel 2 .

Tabel 2. Nilai median, minimum, maksimum IMT/U (persentil), dan tekanan darah subyek

\begin{tabular}{ccccccc}
\hline \multirow{2}{*}{ Variabel } & \multicolumn{3}{c}{ Kasus } & \multicolumn{3}{c}{ Kontrol } \\
\cline { 2 - 7 } & median & Min & Max & Median & Min & Max \\
\hline & & & & & & \\
IMT/U (persentil) & 97,95 & 85,6 & 100 & 37,95 & 5,6 & 83 \\
Tekanan Darah & 120 & 100 & 170 & 100 & 80 & 120 \\
TDS (mmHg) & 80 & 70 & 100 & 65,5 & 50 & 80 \\
TDD (mmHg) & & & & & & \\
\hline
\end{tabular}


Tabel 2 menunjukkan median tekanan darah sistolik pada kelompok kasus lebih tinggi yaitu sebesar $120 \mathrm{mmHg}$ dan tekanan darah diastolik sebesar $80 \mathrm{mmHg}$ dibandingkan dengan median tekanan darah sistolik pada kelompok kontrol sebesar $100 \mathrm{mmHg}$ dan tekanan darah diastolik sebesar $65,5 \mathrm{mmHg}$.

\section{Asupan Gula Sederhana}

Hasil penelitian asupan gula sederhana menunjukkan terdapat perbedaan signifikan antara asupan gula sederhana pada kelompok kasus dan kontrol $(\mathrm{p}=0,039)$. Pada kelompok kasus, 24 subyek $(63,2 \%)$ memiliki asupan gula sederhana yang tinggi ( $>300 \mathrm{mg} /$ hari), sedangkan 14 subyek (36,8\%) memiliki asupan gula sederhana yang normal ( $\leq 300 \mathrm{mg} /$ hari). Pada kelompok kontrol, 15 subyek $(39,5 \%)$ memiliki asupan gula sederhana yang tinggi dan 23 subyek $(60,5)$ memiliki asupan gula sederhana yang normal. Saat penelitian dilakukan makanan yang mengandung gula sederhana yang paling banyak dikonsumsi oleh para remaja antara lain permen, cake, es krim, segala jenis cokelat, semua makanan dan minuman yang manis. Distribusi asupan gula sederhana dapat dilihat pada tabel 3.

Tabel 3. Distribusi Asupan Gula Sederhana Pada Kelompok Kasus dan Kontrol

\begin{tabular}{lccccccc}
\hline \multirow{2}{*}{ Variabel } & \multicolumn{3}{c}{ Kasus } & \multicolumn{3}{c}{ Kontrol } \\
\cline { 2 - 7 } & median & Min & Max & Median & Min & Max \\
\hline \multirow{2}{*}{$\begin{array}{l}\text { Asupan gula sederhana } \\
\text { (mg) }\end{array}$} & 378 & 133 & 2446,3 & 257,2 & 133 & 865,5 \\
\hline
\end{tabular}

Tabel 4. Risiko Asupan Gula Sederhana Terhadap Kejadian Hipertensi Obesitas Pada Remaja Awal

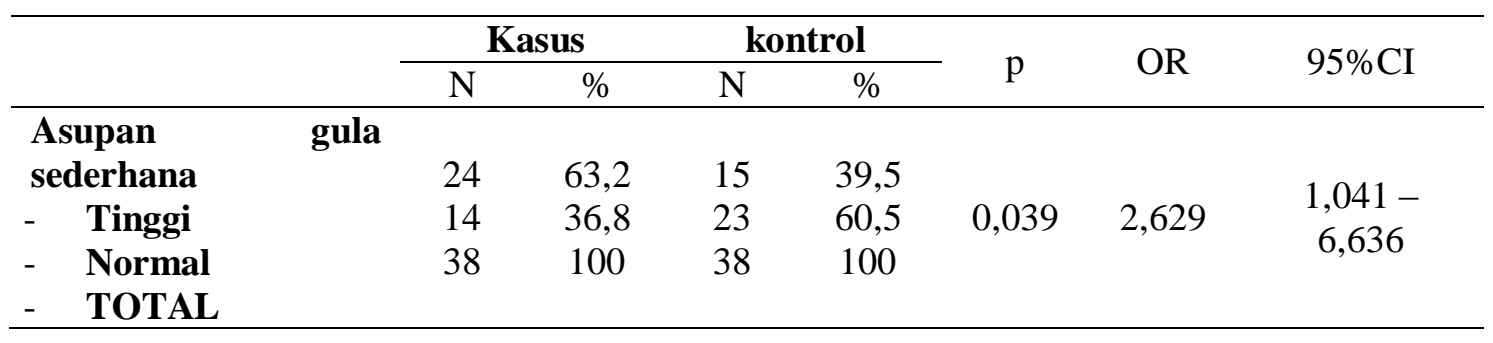

Tabel 4, dapat disimpulkan bahwa asupan gula sederhana pada kelompok kasus lebih tinggi $(63,2 \%)$ dibanding dengan kelompok kontrol $(39,5)$ sehingga asupan gula sederhana memiliki risiko 2,6 kali untuk menjadi hipertensi obesitas pada remaja awal ( $\mathrm{p}=0,039$ : $\mathrm{OR}=2,629$ : $\mathrm{CI}=1,041$ $6,636)$.

\begin{abstract}
Aktifitas Fisik
Penentuan aktifitas fisik dikategorikan menjadi 2 kategori, yaitu tinggi dan rendah. Aktifitas fisik tergolong tinggi jika $>1500$ menit/minggu (3,5 jam/hari) dan tergolong rendah jika <1500 menit/minggu. Hubungan dan besar risiko aktifitas fisik dapat dilihat pada tabel 5 .
\end{abstract}

Tabel 5. Risiko Aktifitas Fisik Terhadap Kejadian Hipertensi Obesitas Pada Remaja Awal

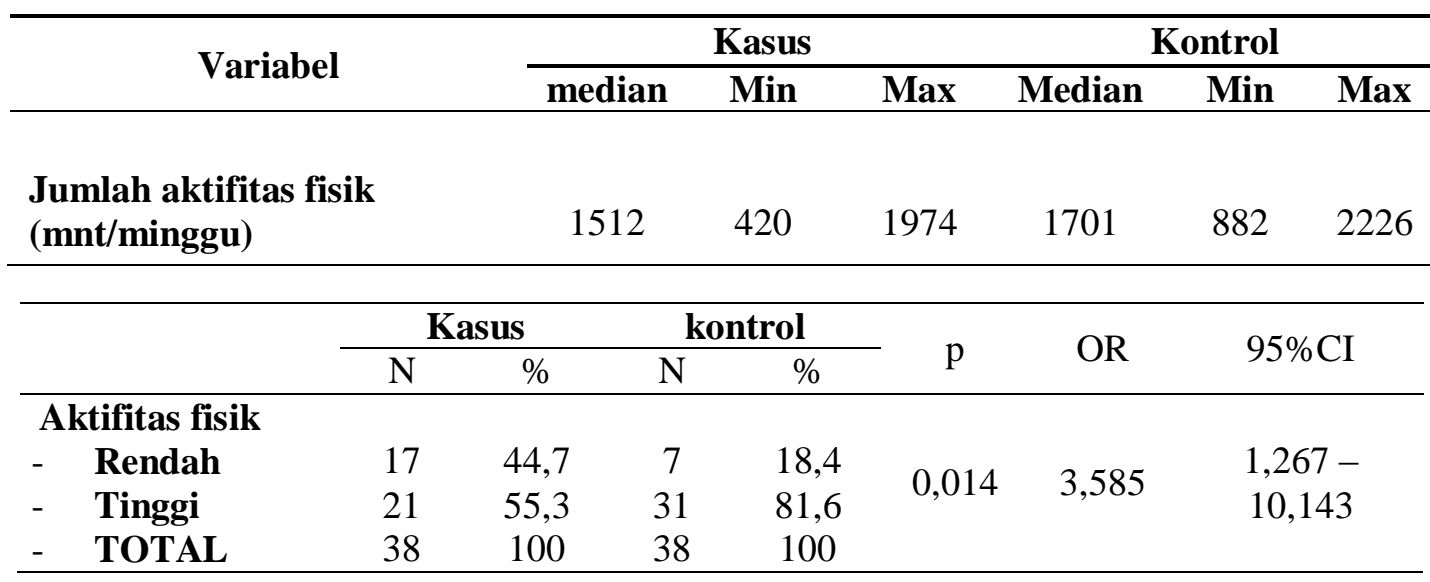


Tabel 5 menunjukkan aktifitas fisik pada kelompok kasus dengan kategori tinggi $(55,3 \%)$ lebih rendah jika dibanding dengan kelompok kontrol (81,6\%). Aktifitas fisik yang rendah merupakan faktor risiko terjadinya hipertensi obesitik pada remaja awal,pada penelitian ini aktifitas fisik mempunyai risiko sebesar 3,5 kali untuk menjadi hipertensi obesitik pada remaja awal $(\mathrm{p}=0,014: \mathrm{OR}=3,585 ; \mathrm{CI}=1,267-10,143)$.

\section{PEMBAHASAN}

Skrinning awal di 5 SMP di Semarang melibatkan 1186 subyek, saat skrinning dilakukan pengukuran berat badan, tinggi badan, lingkar pinggang, tekanan darah dan denyut nadi. Hasil skrinning ditemukan 155 subyek adalah obesitik (13,11\%), 355 subyek hipertensi $(30,03 \%)$ dan 89 subyek termasuk hipertensi obesitik (7,52\%). Menurut Riskesdas tahun 2007 prevalensi hipertensi pada remaja sebesar 9\%, jumlah ini sangat berbeda jauh jika dibandingkan dengan Afrika yaitu sebesar $28,7 \%,{ }^{2}$ sedangkan menurut data riskesdas 2010 sebesar $19,1 \%$ remaja mengalami obesitik.

Masa remaja merupakan masa dimana terjadi perubahan gaya hidup yang mempengaruhi perubahan pola makan. Remaja cenderung memilih makanan yang mengandung tinggi energi, tinggi lemak, tinggi natrium dan tinggi gula, padahal makanan yang memiliki kandungan seperti itu dapat memicu terjadinya hipertensi obesitik. Beberapa penelitian menunjukkan bahwa tidak hanya asupan natrium saja yang dapat menyebabkan hipertensi tetapi asupan gula sederhana juga dapat menimbulkan terjadinya hipertensi. Gula sederhana terdiri dari monosakarida dan disakarida, yang termasuk monosakarida yaitu glukosa, galaktosa dan fruktosa, sedangkan yang termasuk disakarida meliputi sukrosa, laktosa dan maltose. Hasil penelitian ini didapatkan $\mathrm{p}=0,039 ; \mathrm{OR}=2,629$; $95 \% \mathrm{CI}=1,041-6,636$ dimana asupan gula untuk kelompok kasus lebih tinggi dibandingkan dengan kelompok kontrol yaitu sebanyak 24 subyek atau 63,2\% sedangkan untuk kontrol sebanyak 15 subyek atau 39,5\%. Asupan gula sederhana memiliki risiko 2,6 kali untuk menjadi hipertensi obesitik pada remaja awal, hal ini sejalan dengan penelitian di AS yang menjelaskan bahwa mengkonsumsi makanan dan minuman yang mengandung gula dapat meningkatkan rata-rata 76 kalori per hari. ${ }^{15}$ Menurut Framingham Heart Study mengkonsumsi $\geq 1$ kaleng soft drink per hari dapat meningkatkan risiko terjadinya hipertensi dan obesitik. ${ }^{8}$ Penelitian yang dilakukan di Mexico yaitu dengan mengurangi makanan atau minuman yang mengandung gula setiap harinya dapat menurunkan tekanan darah sistolik sebanyak 1,8 $\mathrm{mmHg}$ dan diastolik sebanyak $1,1 \mathrm{mmHg}$ selama kurun waktu 18 bulan. ${ }^{6}$

Salah satu faktor penyebab terjadinya obesitik dapat disebabkan konsumsi gula sederhana jenis fruktosa secara berlebihan. Metabolisme fruktosa yang utama terdapat di hati. Di hati, fruktosa di ubah menjadi glukosa dan disimpan sebagai glikogen hati. Asupan tinggi fruktosa dapat menggagalkan produksi leptin. Leptin adalah hormon yang berfungsi untuk menurunkan nafsu makan dan memicu tubuh untuk menggunakan energi lebih banyak. Jika leptin dalam darah meningkat maka kadar insulin menurun sehingga akan mengurangi nafsu makan, tetapi jika kadar leptin dalam darah rendah maka dapat menyebakan seseorang mengalami obesitik karena tidak ada yang mengontrol nafsu makan. ${ }^{16}$ Penurunan produksi leptin berhubungan dengan asupan tinggi fruktosa yang dapat membahayakan efek regulasi asupan makanan yang membuat kita tidak merasakan kenyang sehingga timbul timbunan lemak dalam tubuh. Sejak fruktosa berada di hati, fruktosa memiliki respon glikemik yang rendah. Walaupun demikian, fruktosa dapat membantu melengkapi lagi glikogen yang ada dalam hati, asupan fruktosa yang berlebihan dapat menyebabkan ketidakseimbangan energi dengan sistem regulasi lemak tubuh, sehingga fruktosa dapat mengakibatkan obesitik. ${ }^{11}$

Hasil food frequency questionare (FFQ) dalam penelitian ini ditemukan pada kelompok kasus sangat menyukai dan sering mengkonsumsi makanan manis, seperti soft drink, agar-agar/ pudding, permen, cake, es krim, segala jenis cokelat, pisang karamel, minuman yang mengandung tinggi gula dan crepes dibandingkan dengan kelompok kontrol yang tidak terlalu menyukai makanan manis. Dalam penelitian ini, jumlah subyek pada kelompok kasus lebih tinggi yaitu sebesar 24 subyek $(63,2 \%)$ daripada subyek pada kelompok kontrol yang hanya 15 subyek $(39,5 \%)$. Hasil food frequency questionare (FFQ) ini sejalan dengan penelitian yang dilakukan di Norwegia terhadap anak-anak, remaja dan dewasa bahwa mereka yang mengkonsumsi makanan dan minuman yang manis berkontribusi terhadap terjadinya hipertensi obesitik. ${ }^{12}$

Uji chi square antara aktifitas fisik dan hipertensi obesitik menunjukkan adanya hubungan yang bermakna $\quad(p=0,014: \quad O R=3,585$; 
95\%CI=1,267-10,143). Pada kelompok kasus, subyek dengan kategori rendah lebih banyak yaitu 17 subyek $(44,7 \%)$ daripada kelompok kontrol yaitu 7 subyek (18,4\%). Kelompok kontrol (normal) dengan kategori tinggi dalam melakukan aktifitas fisik memiliki subyek sebesar 31 subyek $(81,6 \%)$ sedangkan kelompok kasus memilki 21 subyek $(55,3 \%)$. Dalam penelitian ini, aktifitas fisik yang rendah mempunyai risiko sebesar 3,5 kali untuk menjadi hipertensi obesitik pada remaja awal.

Penurunan aktifitas fisik dan atau peningkatan perilaku hidup sedentarian (kurang gerak) mempunyai peranan penting dalam peningkatan berat badan dan terjadinya obesitik. Aktifitas fisik yang rutin dilakukan setiap hari ditambah dengan olah raga dapat membantu melancarkan peredaran darah serta sirkulasi oksigen menjadi lancar. ${ }^{11}$ Hasil kuesioner aktifitas fisik menunjukkan aktifitas fisik yang paling banyak dilakukan oleh subyek adalah menonton tv, tidur, mengikuti kegiatan ekstrakurikuler, les/ kursus, bersepeda, dan bermain. Seseorang dengan aktifitas fisik yang kurang ditambah banyak mengkonsumsi makanan yang manis dan tinggi energi serta rendah zat gizi dapat menyebabkan terjadinya obesitik dan memiliki kecenderungan $30-50 \%$ terkena hipertensi daripada mereka yang aktif. Menurut Framingham Heart Study bahwa aktifitas fisik sedang dan berat dapat mencegah kejadian stroke, aktifitas lain seperti aerobik dapat menurunkan tekanan darah sistolik rata-rata 4 $\mathrm{mmHg}$ dan tekanan darah diastolik $2 \mathrm{mmHg}$ pada orang dengan dan tanpa hipertensi. ${ }^{13}$ Penelitian lain yang dilakukan Michael S. Lauer, MD juga sependapat dengan Framingham Heart Study apabila aktifitas fisik dilakukan setiap hari dapat mencegah terjadinya stroke, kanker, depresi, hipertensi, penyakit jantung dan obesitas. ${ }^{7}$

\section{KETERBATASAN PENELITIAN}

Pada penelitian ini data asupan diperoleh dengan menggunakan food frequency questionare (FFQ) dan data aktifitas fisik diperoleh dengan menggunakan kuesioner aktifitas fisik. Pengisian data asupan tergantung dari kejujuran dan daya ingat responden dalam mengisi FFQ.

\section{SIMPULAN}

1. Prevalensi hipertensi obesitik pada remaja awal adalah 7,5\%.

2. Besar risiko asupan gula sederhana 2,6 kali dalam menyebabkan hipertensi obesitik pada remaja awal.
3. Besar risiko aktifitas fisik 3,5 kali dalam menyebabkan hipertensi obesitik pada remaja awal.

\section{SARAN}

Angka kejadian hipertensi obesitik pada remaja dapat terus bertambah apabila remaja mengabaikan nilai-nilai gizi yang terkandung didalam makanan. Untuk mencegah terjadinya hipertensi obesitik pada remaja awal maka perlu dilakukan pembatasan makanan yang mengandung tinggi gula sederhana. Selain dari makanan, aktifitas fisik juga harus dilakukan setiap hari selama $\leq 1500$ menit/minggu atau sekitar 3,5 jam setiap harinya.

\section{DAFTAR PUSTAKA}

1. Mohammad Yogiantoro, Hipertensi Esensial. Dalam : Ilmu Penyakit Dalam Jilid I Edisi IV. Jakarta. Ilmu Penyakit Dalam FKUI. 2006. Hal 599-603.

2. Francesco P. Cappuccio, Frank B. Micah, Lynsey Emmett, and Sally M. Kerry. Prevalence, Detection, Management, and Control of Hypertension in Ashanti, West Africa. ahajournals.org March 2004.

3. Gregory B. Luma. M.D., and Roseann T. Spiotta, M.D. Hypertension in Children and Adolescents. Am Fam Physician 2006;73:1158-68.

4. Cynthia L. Ogden, Ph.D.; Margaret D. Carroll, M.S.P.H.; Brian K. Kit, M.D., M.P.H.; and Katherine M. Flegal, Ph.D. Prevalence of Obesity in the United States, 2009-2010. NCHS Data Brief No. 82 January 2012.

5. Richard J Johnson, Mark S Segal, Yuri Sautin, Takahiko Nakagawa, Daniel I Feig, Duk-Hee Kang, et al. potential role of sugar (fructose) in epidemic of hypertension, obesity and the metabolic syndrome, diabetes, kidney diasease and cardiovascular disease. Am J Clin Nutr 2007;86:899-906.

6. Richard J. Johnson, L. Gabriela, and Takahiko Nakagawa. The Effect of Fructose on Renal Biology and Disease. Journal of the America Society of Nephrology Vol. 21 No. 12 November 2010.

7. Michael S. Lauer, MD. And What About Exercise? Fitness and Risk of Death in "Low-Risk" Adults. $J$ Am Heart Assoc 2012.

8. Diana I. Jalal, Gerard Smits, Richard J. Johnson and Michel Chonchol. Increased Fructose Associates with Elevated Blood Pressure. Journal of the American Society of Nephrology Vol 21 No. 9 September 1, 2010.

9. B.Gelaye, L. Revilla, T. Lopez, S. Sanchez, andM.A.Williams, "Prevalence of metabolic syndrome and its relationship with leisure time 
physical activity among Peruvian adults," European Journal of Clinical Investigation, vol. 39, no. 10, pp. 891-898, 2009.

10. Rachel K. Johnson, Lawrence J. Appel, Michael Brands, Barbara V. Howard, Michael Lefevre, et al. Dietary Sugars Intake and Cardiovascular Health. American Heart Association. August 24, 2009.

11. Larry Wasserman, MS, NASM-CPT. Fructose is a 'Simple' Sugar. 2009.

12. Nina C Øverby, Inger TL Lillegaard, Lars Johansson and Lene F Andersen. High intake of added sugar among Norwegian children and adolescents. Submitted 24 February 2003: Accepted 2 July 2003.

13. Herve' Besson, Søren Brage, Rupert W Jakes, Ulf Ekelund, and Nicholas J Wareham. Estimating physical activity energy expenditure, sedentary time, and physical activity intensity by self-report in adults. Am J Clin Nutr 2010;91:106-14.

14. M.D. Esler, N. E. Straznicky,N. Eikelis, K.Masuo,G. Lambert, and E. A. Lambert, "Mechanisms of sympathetic activation in obesityrelated hypertension," Vol. 48, pp. 787-796, 2008.

15. Vasanti S Malik, Matthias B Schulze, and Frank B Hu. Intake of sugar-sweetened beverages and weight gain: a systematic review. Am J Clin Nutr 2006;84:274-88.

16. Jean Welsh, RN, MPH, and William Dietz, MD, $\mathrm{PhD}$. Sugar-Sweetened Beverage Consumption Is Associated With Weight Gain and Incidence of Type 2 Diabetes. Volume 23, Number 4, 2005. Clinical Diabetes. 